\title{
COMPLEX ARRHYTHMIA PROBABLY OF TRAUMATIC ORIGIN
}

\author{
By Edmund Finsterbusch, M.D., Vienna \\ From the Cardiac Department, Royal Free Hospital; Consulting Cardiologist to the Ministry of Pensions
}

A married man, aged 49, assistant manager of a factory, was admitted to hospital on May 30 , 1945, complaining of exhaustion, palpitation, dyspnea on slight exertion, giddiness and faint turns. He states that his symptoms have been present since January 2, 1945, when he was crushed between two lorries, the one being stationary, the other running back. The right anterior costal edge is said to have taken the full impact of the crushing force. Directly upon the accident he was taken to the Surgical Ward (St. John and St. Elizabeth's Hospital), and remained there for a fortnight. His recollection of events during his stay in that hospital is rather hazy, he remembers, however, that he had had no solid food for the first four days. He had abdominal pain under the right costal edge for about four weeks, and became aware of a fluttery feeling in the neck about three weeks after the accident.

No attention was paid to his cardiovascular system till his family doctor noticed irregularity of the heart beat on routine examination a month after the accident, February 2, 1945.

He had had no serious illness previously, and his medical attendant during the last five years describes him as a normal, active man who, apart from mild respiratory infections, never presented any serious symptom. Patient himself emphasized that prior to the accident he led a very active life and was a keen walker.

Examination. He is a tall, strongly built, well-covered man. No chest deformity is found. The cardiac impulse is imperceptible ; the sounds are distant. The heart action is completely irregular, and there is a considerable pulse deficit on minute count. A short, insignificant systolic murmur in apical area. B.P.: I50/90. No sign of congestion. Brachial arteries moderately thickened, straight. Over the left pulmonary base scanty fine crepitation. Ophthalmoscopy reveals normal fundi. No abnormalities are found in his nervous system. On external examination of the abdomen nil abnormal detected.

On radioscopy, normal-shaped, rather vertical heart silhouette. Irregular pulsations of low amplitude. Low diaphragm. Vascular pedicle of normal appearance. Cardiothoracic ratio, 53 per cent. Circulation time, arm to tongue (calcium gluconate): I8 seconds.

\section{Electrocardiographic Analysis}

In lead I of the cardiogram taken on June 5 , I 945 (Fig. I) the $\mathrm{P}$ waves preceding the fourth and the following QRS complexes are just discernible. There is a gradual slowing down of the auricular rate, viz., $\mathrm{P}_{4}-\mathrm{P}_{5}=0.48$, $\mathrm{P}_{5}-\mathrm{P} 6=0.53, \mathrm{P} 6-\mathrm{P}_{7}=0.54, \mathrm{P}_{7}-\mathrm{P} 8=0.54$ second. P-R4, P-R5, P-R6 measure $0.20,0.25$ and 0.28 second respectively. $\mathrm{P}_{7}$ is blocked and hidden in the final deflection of QRS 6. The last $P$ is conducted after 0.16 seconds.

Auricular rate $\mathrm{I} I 6$, prolonged A-V conduction (Wenckebach period), dropped beat.

In lead II (Fig. I) the $\mathrm{P}$ waves vary in shape, width and spacing; some are bifid and others flat-topped. The duration of the P-P intervals ranges from 0.28 to 0.88 second. The record consists, in that order, of two periods of $2: \mathrm{I}$ block, one period of $3: 1$ block, one normal ventricular response, and of a period of auricular silence ( 0.88 second) which is treble and double respectively of the usual P-P cycles. That may be interpreted as S-A block. The one $\mathrm{P}$ but last $\left(\mathrm{P}_{9}\right)$ is superimposed on the $\mathrm{S}-\mathrm{T}$ segment of the QRS IV. Sinus tachycardia and arrhythmia at an average rate of 140 . The T IV is the smallest of all. Note the preceding $T$ waves merged with $P$ waves.

The cardiogram taken on June $7, \quad 1945$ (Fig. 2) displays in lead I an equally spaced sinus bradycardia at a rate of 46 a minute. $\mathrm{P}$ waves low, wide and bifid. The $\mathrm{P}-\mathrm{R}$ inter- 


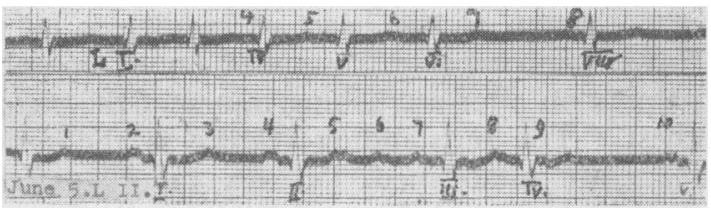

Fig. I.-June 5, I945. Lead I and lead 2. For complete legend see text.

vals probably 0.20 second. The measurements being conjunctural because the departure of the ascending limb of the $\mathrm{P}$ waves from the isoelectric line cannot be definitely ascertained; on the other hand the time-marker rotates at a varying speed. The $\mathrm{P}-\mathrm{P}$ intervals are I.24 second, which is an almost multiple of the P-P intervals in lead CR IV (Fig. 2). Whence the 'bradycardia' is obviously due to sinoauricular block or to the inability of the pacemaker to generate impulses.

Variform $\mathrm{P}$ waves occur in lead CR IV (Fig. 2), e.g., $\mathrm{P}_{5}$ bifid, $\mathrm{P}_{7}$ narrow and peaked, $\mathrm{P}_{10}$ wide and low. $\mathrm{P}_{2}, \mathrm{P}_{4}, \mathrm{P} 6, \mathrm{P} 8$ and $\mathrm{P}_{9}$ are not conducted. The last $\mathrm{P}-\mathrm{R}$ interval is 0.24 second. Auricular tachycardia and arrhythmia, with sudden slowing and quickening, and varying $\mathrm{A}-\mathrm{V}$ block $2: \mathrm{I}$ and $3: \mathrm{I}$.

On June 8, I945, the lead CR IV (Fig. 3) begins with a run of three auricular beats at a rate of $i 90$. The first only being conducted, the second $\mathrm{P}$ is superimposed on the $\mathrm{S}-\mathrm{T}$

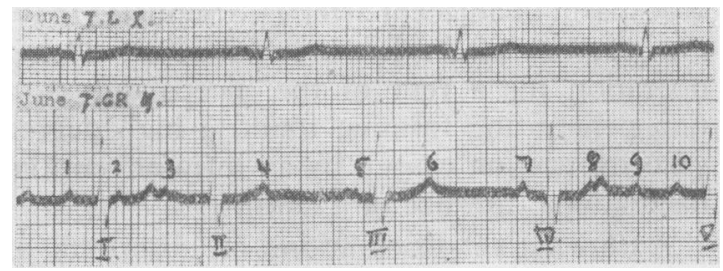

Fig. 2.-Lead I, lead CR 4. June 7, г945. See text.

segment of the preceding ventricular complex, the third $\mathrm{P}$ barely touching the descending limb of the $\mathrm{T}$ wave of the same beat. Then follows a period where there is no evidence of electric activity, viz., $\mathrm{P}_{3}-\mathrm{P}_{4}$, measuring $\mathrm{I} . \mathrm{I} 2$ second, i.e., about the fourfold of the previous P-P cycles. The second half of the record shows five equidistant auricular contractions at a rate of 120 , with $2:$ I ventricular responses. $\mathrm{P}_{5}$ and $\mathrm{P}_{7}$ are hidden in the final deflections of the preceding beats. There are two types of $P$ waves nicely arranged in two separate groups. One group before and the other after the standstill of the pacemaker. The first one containing small and peaked $P$ waves, the second containing wide and bifid $P$ waves. To sum up, there is auricular tachycardia, S-A block, slowing down of the auricular rate, auriculo-ventricular and intra-auricular block.

The lead CR IV (Fig. 4) was taken on June 20, I945, after hypodermic injection of $\mathrm{I} / 75$ of a grain of atropine. There is auricular tachycardia with irregular discharge of the

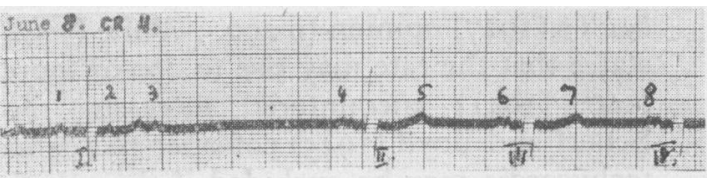

Fig. 3.-Lead CR 4. For legend see text. June 8, 1945.

pacemaker at an average rate of 222 a minute. $\mathrm{P}_{2}, \mathrm{P}_{4}, \mathrm{P}_{9}, \mathrm{P}_{12}$ and $\mathrm{P}_{13}$ are not conducted, the $\mathrm{P}_{4}$ being buried in QRS II, the $\mathrm{P}_{2} 2$ in the aberrantly conducted QRS VIII. $\mathrm{P}_{5}, \mathrm{P} 6$ and $\mathrm{P}_{I_{3}}$ are merged in varying fashion with the $\mathrm{T}$ waves. It is to be noted that the $P$ waves, as far as they are visible, are of small monophasic type, and the tachycardia is maintained throughout the record. There is no evidence of sinus block, although there is disturbance of the $\mathrm{A}-\mathrm{V}$. conduction.

To summarize there is a complex arrhythmia consisting of supraventricular tachycardia with prolonged $\mathrm{A}-\mathrm{V}$ conduction, occasional Wenckebach periods, varying A-V block,

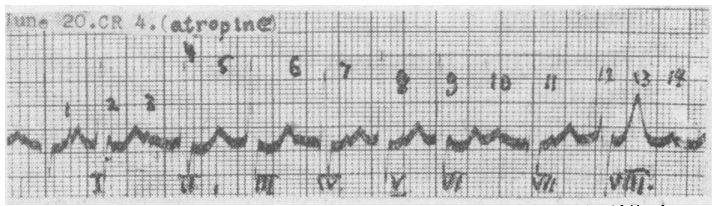

Fig. 4.-Lead CR 4, after $1 / 75$ of a grain of atropine. June 20, 1945. See text.

intervals of standstill of the whole heart, viz., sinus block, and irregular discharge of the pacemaker. The variety of $\mathrm{P}$ complexes associated with varying $P-R$ intervals suggests the wandering of the pacemaker. The heart action is grossly irregular, long and short ventricular cycles irregularly mingling, so that the record appears to be at first glance an auricular fibrillation. Indeed, on bedside, this arrhythmia cannot be distinguished from auricular fibrillation. 
The exact designation of the origin of the pacemaker of 'supraventricular tachycardia' is difficult, sometimes even impossible.

The following features point to nomotopic pacemaker :

I. The highest minute rate recorded in our case is 214 at rest. There is no unanimity as to the maximum rates compatible with the diagnosis sinus tachycardia. According to Lewis (1925) the rate in simple tachycardia may range up to 180 ; in Wenckebach's (1927) opinion to 200. White (1944) states that the rate may rise to 200 or more. Katz (I94I) encountered rates to 180. Scherf and Boyd (1945) consider that sinus tachycardia may be excluded if the minute rate exceeds 200. A sinus tachycardia of 200 a minute and more was studied by Field et al. (1934) and ascribed to the failure of vagus inhibition.

2. The absence of a definitely anomalous inverted $P$ wave. There was no opportunity to record a premature auricular beat or a premature start of a paroxysm nor the pause immediately following its termination.

3. The chronic character of the arrhythmia.

4. The rapid variations of the rate, the remarkable slowing down of the whole heart, the association of $\mathrm{A}-\mathrm{V}$ block with sinus block indicate variations of vagal tone to which the sinus is greatly subordinated, the right vagus chiefly supplying the S-A node.

5. The abolition of the gross irregularity and quickening of the rate to 222 a minute by hypodermic injection of $1 / 75$ of a grain atropine.

6. Digitalis and quinidine were ineffective to decrease the rate.

Carotid sinus pressure was applied without any definite clinical or electrocardiographic effect. The other sinus reactions to exercise, change of posture, deep inspiration, could not be applied on account of lack of co-operation on the side of the patient, and on account of his symptoms.

According to his history and his doctor's report that no arrhythmia was noticed previously to the accident, the traumatic etiology of this malady can be considered a probability and, under this aspect, discussed.

\section{Discussion}

The patient described presented symptoms of contusion of the heart as giddiness, faint turns, apprehension, dyspnoea on effort and palpitation after a crushing injury of the right chest. The outstanding feature is the permanently established, i.e., six months after the accident, complex arrhythmia. So far as I am aware no arrhythmia of that type has been recorded in a case of cardiac contusion.

Pathogenesis. An incontestable explanation of pathogenesis cannot be offered without dissection. However, careful analysis of the clinical condition, with due consideration of the pertinent experimental and pathophysiological facts may guard against mere conjuncture.

The chronicity of the traumatic cardiac condition is to be ascribed to irreversible structural changes of the myocardium and the specific tissues. Permanent tachycardia per se is usually associated with organic cardiac affections.

Fibrous scars within the myocardium or conductive system, subsequent to mechanical vascular laceration or ischaemic extravasation, are the most probable anatomical lesions in our case, the patient's middle age being certainly a predisposing factor. These cicatrices may interfere with the blood supply to the sinus node, viz., conductive tissue, either through vascular obliteration or by causing vasospasm in adjacent arteries. Schuele (1937) on exposure of the left brachial artery during operation for a rent of the biceps due to a non-penetrating trauma, found a high degree vasoconstriction caused by an intra-adventitial haematoma the size of a lentil.

Authoritative observations on disorders of the heart beat through impairment of blood supply of the specific tissues were made by Rothberger and Scherf (I93I). These authors produced in experimental animals through ligature of arteries of sinus node partial sinus block with dropped beats, wandering pacemaker and interference between sinus and A-V arrhythmia.

Discussing the pathogenesis, viz., pathophysiology of clinical concussion of the heart, Schlomka (I933) refers to his not infrequent autoptic findings in experimental animals, of small or minute haemorrhages within the myocardium and conductive system, resulting from ischaemic extravasation secondary to 
traumatic vascular spasm, which is analogous with the experimental coronary spasm of Drury and Smith (1.924), and with the segmentary vascular spasm in peripheral arteries resulting from injury of adjacent tissues.

Winternitz (1928) diagnosed in a man of 62 a sinus bradycardia, due to structural changes of the sinus node, which were substantiated on necropsy by an almost completely obstructing thrombosis of the artery of the sinus node.

The irregular variations in the rate of the heart indicate a high degree imbalance of the vagal tone, which, in health, is reflexly maintained by afferent impulses in the sino-aortic nerves. Traumatic lesions of the cardiac plexus, viz., mechanical stimulation of nervous terminals, may account for that. The cardiac plexus lies in the concavity of the aortic arch, partly between aorta and pulmonary artery, and partly between the former and pulmonary veins. The afferent fibres of the plexus arising from carotid sinus, aortic arch, aortic body, left ventricle, both auricles and roots of venae cavae join with the vagus and sympathetic, which exchange multiple fibres with each other so that they cannot be clearly separated within the cardiac plexus. A great proportion of these fibres arises from the venous, i.e., right side of the heart, which is more frequently exposed to traumatization, owing to its proximity to the anterior chest wall. That implies increased vulnerability of the afferent fibres also, which, under normal conditions, help to stabilize the cardiac rhythm.

Dressler (1928) presented an electrocardiographic study with features partly analogous to our case. There was a completely irregular sinus arrhythmia, with variform $P$ waves and varying conduction times in a woman of 40 , with chronic mitral and tricuspid stenosis. Discussing the pathogenesis of the condition, the author emphasizes the significance of the vagal tone, yet, in cases of permanently established sinus arrhythmia of complex nature, he assumes anatomical lesions.

Medico-legal aspect. . His past history is irrelevant in respect of cardiac disease. His family doctor clearly stated he had not noticed any cardiac abnormality prior to the accident and, above all, the patient said he was quite fit and capable of following his employment up to the critical day.
Although the disorder of cardiac function had not been diagnosed as such immediately after the accident, it is obvious that the symptoms were then so severe as to force the patient to strict bed rest in a surgical ward for a fortnight, and subsequently to render him incapable up to date. Yet a clear-cut causal nexus between the trauma and the disability is not established, for no electrocardiographic records were made before and immediately after the accident.

\section{Summary}

A patient is described who manifested the syndrome of contusion of the heart consorted with an established complex arrhythmia.

The differential diagnosis of supraventricular tachycardia is discussed.

Structural lesions involving the conductive system and the terminals of the cardiac plexus are assumed as the underlying pathology.

The medico-legal issue of the case is considered.

I wish to express my indebtedness to Dr. Jenner Hoskin for passing this case to me and for facilities granted. Also my acknowledgement is due to Miss P. Seymour for the care in recording and to Dr. Gunasekara for supplying the past history.

\section{Addendum}

After preparation of this article, Master (1946) expressed the view that the forceful impact of the chest wall against the heart results in damage to the heart muscle, usually in the form of haemorrhages. Contusion of the heart may produce disturbances of the heart function manifested chiefly as disorders of the rhythm.

\section{BIBLIOGRAPHY}

DRESSLER, W. (1928), Verhandl. d. deutsch. Gesellsch. f. Kreislaufforsch, 160 .

DRURY and SMITH (I024), Heart, 2 quoted by Schlomka.

FIELD, H., JUN., BARKER and ALEXANDER (1934), Am. Heart

F., 9, 298.

KATZ, L. (I94I), Electrocardiography, H. Kimpton.

LEWIS, T. (1925), The Mechanism and Graphic Registration of the Heart Beat, Shaw and Sons.

MASTER, A. M., New York State F. Med., 46, 2634.

ROTHBERGER, C. J. (1931), Ergebn. d. Physiol., 32, 750.

SCHERF and BOYD (1945), Clinical Electrocardiography, W. Heinemann.

SCHLOMKA, G., and SCHMITZ, M. (1932), Zeitschr. ges. exper. Med., 85, $17 \mathrm{I}$.

SCHUELE, F. (1937), Zentralbl. f. Chir., $23,1340$.

WENCKEBACH and WINTERBERG'(1927), Die Unregelmässige Hertztätigkeit, Leipzig.

Hertztatigkeit, Leipzig.
WHITE, P. D. (1944) Heart Disease, Macmillan.

WINTERNITZ, M. (1928), Verh. d. deutsch. Ges. f. Kreislaufforsch, 176. 